\title{
The Application of "Course Depreciation" in Credit Bank for Credit Accumulation and Exchange
}

\author{
Yang Zhao* \\ Science and Technology and Development Planning Office \\ Yunnan Open University \\ Kunming, China \\ 42755044@qq.com
}

\begin{abstract}
There are some obstacles in the credit bank construction, such as contradictions among registration validity, learning outcomes exchange and educational equality. According to the function of credit bank, the author originally proposes the conception of "course depreciation" for solving the contradictions mentioned above. In order to solve the contradictions between lifelong registration validity, lifelong learning outcomes exchange and continuous knowledge updating, the "course depreciation digit" is set in the credit bank course code, and the digit is applied when accumulation and exchange will be good solutions. In addition, it will achieve the continuous learning outcomes accumulation and exchange, society requirement of personnel training, and educational equality.
\end{abstract}

Keywords-Course Depreciation; Course Depreciation Coefficient; Credit Accumulation; Learning Outcome Exchange

\section{INTRODUCTION}

Lifelong education system should include all kinds of education forms that run through all stages of one's life. The establishment of a lifelong education system is an inevitable trend in the development of education itself and a basic trend in the development of education in the world. The report of UNESCO's 21st Century Education Committee mentioned: "Lifelong education should have the advantages of flexibility, diversity and easy access to time and space instead of the limitation of time and space in people's life." The Second International Conference on Technical and Vocational Education also pointed out: "In order to facilitate the implementation of lifelong learning, management must be flexible in course-planning and course setting, offering learners the convenience of entering, leaving and re-entering learning." [1]

The establishment of a learning outcome certification system and a "credit bank" system is an important part of the "lifelong education system and mechanism construction pilot". "Credit bank" is an authoritative certification institution for lifelong learning outcomes of all social members. Through accumulation, recognition and exchange of credits, learners" learning experiences can be continued and their learning outcomes can be maximized. It can effectively connect and mutually recognize learners learning outcomes, thus establishing an "overpass" for lifelong learning. It enables learners to obtain the learning outcomes of various educational institutions at all levels through continuous or intermittent

Fund Project: Key Social Science Project of the Science Research Fund of Yunnan Education Department "Construction of Integrated Talents Training Mode in Higher Vocational Education -Taking the Major Communication Engineering as an Example" (Project No.: 2015Z169) learning, thus obtaining the required academic (position) or qualification (quality) certificates, and truly promoting the lifelong education system and the construction of a learning society. From the practical perspective of the construction of lifelong education system and credit bank system, this paper makes in-depth analysis and reflection on some problems and contradictions in credit accumulation and exchange, such as the contradiction between the prescribed registration validity and the lifelong learning outcome validity, contradiction between course knowledge updating and the lifelong validity of course credits, as well as the contradiction between the learning outcomes and educational result equality. This paper tries to put forward the concept of "course depreciation" by setting "course depreciation coefficient" in the credit bank course code system and scientifically applying "course depreciation coefficient" in the accumulation and exchange of learning outcomes, so as to find a solution to the three contradictions above. In order to improve the accumulation and exchange efficiency of learners learning outcomes, the function of "intelligent reminder of course depreciation" is proposed from the perspective of learners-friendly service.

\section{Functions And Key Points of CRedit Bank System}

A credit bank creates a life-long valid account for each registrant, allowing them to accumulate credits and transfer learning results throughout their life in the system. In a credit bank, a learner can earn a certain amount of credit after completing one course. Credit is not only the basic score unit for learners to participate in courses, trainings, refresher courses, various qualification certifications, but also the basis for storage, transformation, consumption and settlement of learning results and the basis for learners to obtain various certificates or resources. The credit bank allows users to concentrate or interrupt their study time, and study in irregular semester. In spite of several interrupts, the previous study experience can still be converted into credits and stored in the credit bank account of the learner. After the courses, knowledge and skills learned by the learners have passed the certification; they are converted into corresponding credits according to the established credit standards and deposited into the credit bank system. When the credits accumulation reaches the specified requirements, they can be exchanged through the "credit bank"-the exchange for academic qualifications (positions) or qualification certificates, relevant resources to 
realize the function of "installment time deposit" similar to that of the bank[2].

The establishment of credit bank system can facilitate learners to choose courses and levels suitable for their own actual learning. They can improve their learning levels at any time according to actual needs, avoid repeated learning, save time and energy costs of learning, and maximize learning results. This is conducive to the formation of a continuous life-long "climbing" learning model, which is of great significance for effectively promoting China higher education reform and the realization of educational equity.

Credit banks generally have two major functions-recognition of learning outcomes and credit accumulation and exchange. Its structure can be divided into five parts: credit standard subsystem, credit mutual recognition subsystem, credit accumulation subsystem, credit exchange subsystem and credit integrity subsystem [5]. The core elements of these five subsystems have their own emphases. They are interrelated and mutually supporting. The credit bank subsystem and its core elements are shown in Table I.

TABLE I. SUBSySTEMS AND CORE ELEMENTS OF CREDIT BANKS

\begin{tabular}{|c|c|c|}
\hline Subsystem name & Subsystem composition & $\begin{array}{c}\text { Subsystem core } \\
\text { elements }\end{array}$ \\
\hline $\begin{array}{c}\text { Credit standard } \\
\text { subsystem }\end{array}$ & $\begin{array}{c}\text { The national occupation } \\
\text { (professional) directory, } \\
\text { course standards, various } \\
\text { levels of education } \\
\text { convergence course standards. }\end{array}$ & $\begin{array}{c}\text { Standards of certification, } \\
\text { exchange and integrity }\end{array}$ \\
\hline $\begin{array}{c}\text { Credit mutual } \\
\text { recognition } \\
\text { subsystem }\end{array}$ & $\begin{array}{c}\text { Acquisition, storage and } \\
\text { accumulation of credits }\end{array}$ & $\begin{array}{c}\text { Content and process of } \\
\text { accumulation }\end{array}$ \\
\hline $\begin{array}{c}\text { Credit accumulation } \\
\text { subsystem }\end{array}$ & $\begin{array}{c}\text { Mutual recognition, exchange } \\
\text { and compensation of credits }\end{array}$ & $\begin{array}{c}\text { Level, type, direction, } \\
\text { unit, subject, content, } \\
\text { process and result of } \\
\text { authentication }\end{array}$ \\
\hline $\begin{array}{c}\text { Credit exchange } \\
\text { subsystem }\end{array}$ & $\begin{array}{c}\text { Design of exchange rate and } \\
\text { gradual exchange mechanism } \\
\text { establishment of progressive } \\
\text { exchange mechanism }\end{array}$ & $\begin{array}{c}\text { Unit, subject, process and } \\
\text { result of conversion }\end{array}$ \\
\hline $\begin{array}{c}\text { Credit integrity } \\
\text { subsystem }\end{array}$ & $\begin{array}{c}\text { Integrity of learners } \\
\text { themselves, issuing agencies } \\
\text { and accreditation agencies }\end{array}$ & $\begin{array}{c}\text { Dishonesty behavior and } \\
\text { its treatment, process and } \\
\text { results }\end{array}$ \\
\hline
\end{tabular}

Credit accumulation and exchange subsystems are the two most critical subsystems of credit bank. Accumulation means that different people receive the different education and trainings at different times and on different occasions, after passing the examination, they can obtain corresponding credits and learning records, which are all stored in individual learning accounts. Exchange means after individuals have obtained enough valid credits of different types in different occasions, they can make two-way or multi-way exchanges according to their own needs and objective standards. They exchange their required academic certificates, qualification certificates and other life-long learning products.

\section{SEVERAL PROBLEMS IN THE CONSTRUCTION OF} LIFELONG EDUCATION SYSTEM AND CREDIT BANK SYSTEM

In recent years, many countries have made great efforts to establish the certification, accumulation and exchange system of learning outcomes adapted to their own conditions. The research and practice on the construction of "credit bank" system in our country are at the exploratory stage. Based on China's national conditions and the reality of educational development, the advanced experience explored by other countries cannot be completely copied into the construction of credit banks in China. As far as the current situation in China is concerned, institutions of higher education, mainly open universities, have accumulated some experience and laid a certain foundation in the mutual recognition and exchange of credits, but have not yet formed a mature system and a comprehensive and effective implementation plan. "Credit bank" covers a wide range of contents. They include the innovation and improvement of many systems, including admission system, exchange system, credit system, course system, educational system, elective system and evaluation system. It will certainly promote the reconstruction of teaching concepts, the exchange of teaching modes, the integration of teaching resources, the reconstruction of teaching system and other deep links.

The establishment of credit bank system is a huge and complicated system engineering, which requires not only overall macro design but also detailed consideration in the implementation details. At present, there are still many deep-seated obstacles in the construction of credit banks, which directly affect the process of construction and realization of credit bank [3]. In the process of research on the construction of credit bank, the author found the following contradictions between the current education situation and the construction of credit bank and the realization of the lifelong education system in terms of timeliness and lifetime:

\section{A. Contradictions between prescribed registration validity and the lifelong validity of the learning outcome}

Although most secondary vocational schools and higher education schools in our country have carried out credit system reform to varying degrees, the current credit system is basically the academic year credit system, which stipulates the registration validity. In order to obtain a graduation certificate, learners must complete their studies and pass the examination within the registration validity according to the requirements of the course system for training professional talents in the school. Otherwise, those who complete their studies beyond the registration validity will only be able to obtain a certificate of incompletion. For example, most higher education institutions in our country stipulate that the registration validity is 6 years, while it is 2 to 8 years in radio and television universities (different years in specialized and undergraduate schools). If a learner cannot obtain the required credits during his/her period of membership, he/she can only passively be a dropout or not a graduate and terminate his/her registration, which is equivalent to "canceling the account" in banking business. In fact, this is contradictory to the lifelong validity of learning outcomes advocated by the lifelong education system, to the lifelong validity of learning accounts and learning outcomes in credit banks, and directly hinders the lifelong accumulation and exchange of learning outcomes. 


\section{B. Contradiction between course knowledge updating and lifetime validity of course credits}

In a practice before, a learner's registration validity in the credit bank system is simply defined as life-long validity, and his course credits obtained are also defined as life-long validity, which can be accumulated and exchanged in the credit bank continuously for life in order to solve the above contradictions. However, this will bring about another problem under the current background of rapid knowledge updating, if all credits are stipulated to be valid for life, the course knowledge learned in the early stage will be out of touch with the continuously updated knowledge of modern disciplines, which will not satisfy the continuous progress of talent cultivation, thus causing some problems such as the aging of learners' knowledge and their inability to adapt to social development.

At present, the development of natural science, information science, social science and other disciplines is very rapid, and the corresponding course content is constantly adjusted accordingly. If the credits of the course are stipulated to be valid for life, and the learners use the credits obtained a long time ago to exchange the current certificates (academic certificates, professional qualification certificates, etc.), the knowledge system mastered by the learners will not match the actual development and application of the disciplines, and the trained talents will also be out of line with the social needs.

\section{The Contradiction between the Three Levels of Educational Equity}

The construction of a lifelong education system and credit bank system is an important way to promote the realization of educational equality. Educational equality mainly includes three levels of requirements:

- It ensures that everyone has equal rights and obligations to receive education;

- It provides relatively equal educational opportunities and conditions for people;

- Relative equality of educational success opportunities and educational effects, that is, each student can reach a basic standard after receiving the same level of education, including substantial equality in students' academic performance, equality in educational quality and equality at the target level.

Among them, "ensuring everyone has the opportunity to receive education" is the premise and foundation, "providing relatively equal educational opportunities and conditions" is the further requirement, and is also the premise of "educational success opportunity" and "relatively equal educational effect". In general, these three levels are summarized as: equal starting point, process and result.

In the current educational practice, the regulations on the registration validity limit the learners' educational opportunities and conditions, and the educational success opportunities in age and duration. If the credits of the course remain valid for life, it will bring about the problem of equal educational outcomes.

\section{SOLUTION- “COURSE DEPRECIATION” AND ITS SySTEM APPLICATION}

In order to solve the above contradictions, the author tries to put forward the concept of "course depreciation", adds a "course depreciation coefficient" to the course information during the construction of the credit standard subsystem, and applies this coefficient systematically and scientifically in the credit bank system. The setting and application of "course depreciation coefficient" can be started from the following aspects:

\section{A. The education authorities shall establish an open course standard system and information catalogue}

The credit standard subsystem is the foundation for credit banks to recognize, accumulate and exchange credits, and consists of national vocational (professional) directory, course standards, and course standards for linking various levels and types of education. It is of great significance to establish an authoritative and open course standard system and related information catalogue by the education authorities in the construction of the credit standard subsystem. The course standard system and the corresponding information catalogue should explain the course name, course information, course knowledge content framework, course validity (i.e. course depreciation coefficient), course evaluation rules and other information of different courses and disciplines (this article only discusses the course depreciation coefficient).

\section{B. The meaning and function of course depreciation coefficient}

The course depreciation coefficient is expressed in "year", which indicates the time how many years a course expires. For courses with more traditional and fixed knowledge, the depreciation coefficient can be set higher and become invalid in a longer year. And courses with fast knowledge updating have low depreciation coefficient and are ineffective in a short period of time. Specifically, the course has expired and its credits are no longer valid, if:

$$
(a-b)>=r
$$

In formula (1), $a$ is current year, $b$ is year when credits were obtained, $r$ is course depreciation coefficient.

If learners want to continue participating in the accumulation and exchange of credits, credits must be revalidated through the prescribed credit updating. The school offering the course can decide how to renew the credits of depreciation and how to revalidate them according to the characteristics of the course, such as a supplementary examination, a renewal of the knowledge module of the course and a renewal of the course and so on.

There are many majors with several required courses in the education system. Knowledge of some courses is updated quickly and some are slow. If the validity of the registration and course credits is set to be valid for life, it will lead to the problem that some courses are aging and cannot meet the requirements of professional knowledge and social needs when learners exchange learning results. Therefore, before the course was put into the credit bank's database, the education authorities (or discipline expert committee) shall set the 
depreciation coefficient of the course according to the level, nature and content characteristics of the course. In this way, the same courses in different colleges and institutions can be depreciated according to the course standard system and course depreciation coefficient. This provides the basis for course depreciation for credit accumulation and exchange.

With the concept of "course depreciation", it is possible to promote the continuous updating of the learner's knowledge system to meet the needs of personnel training and society on the premise of ensuring the lifetime registration validity and the continuous accumulation of learning outcomes. This reasonably solves the contradiction between the prescribed lifetime registration validity and the lifetime validity of learning outcomes, the renewal of subject knowledge and the lifetime validity of course credits, and achieves the equality of educational results from a certain angle. At the same time, the application of course depreciation can urge learners to control their learning progress, exchange their learning results as soon as possible, and promote the generation of their learning motivation.

\section{Setting "Course Depreciation coefficient" in the Course Code of Credit Bank Management System}

In order to manage courses and credits in the credit bank system, all courses in the system must be assigned codescourse ID according to certain rules. To apply the course depreciation coefficient to the credit bank system, the "Course Depreciation coefficient" can be set to represent the course depreciation information. Assuming that a credit bank management system has a course ID of 9 digits, then two digits are added to its original coding principle as "course depreciation coefficient digits" (generally speaking, the effectiveness of course knowledge is mostly within 100 years, and the learning life of a natural person is also within 100 years, so only two digits are considered as depreciation coefficient digits, and the range of 0-99 is sufficient), namely, digits 10-11 are "course depreciation coefficient digits"(as shown in Fig. 1). For example, the number of $10-11$ in a certain course is 06 , which means that the course expires in 6 years. The learner can take part in the accumulation and exchange of credits from the course within 6 years starting from the time of obtaining credits from the course. In more than 6 years, these credits can no longer take part in the accumulation and exchange of credits They cannot be used until they need to be updated to take effect again.

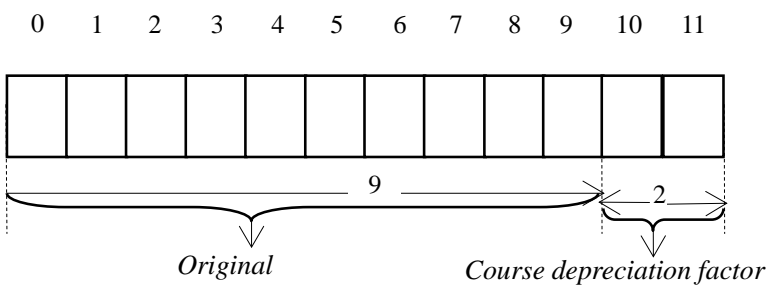

Fig.1. Adding Course Code of Depreciation Factor Bit

When a learner applies for a certificate of credit exchange, the system not only checks whether the learner has obtained the credits required by the corresponding certificate course system, but also checks the depreciation coefficient of each course in the certificate. If all the courses are within the period of validity, it means that the learner's knowledge can meet the professional requirements and the knowledge is not aging, and he is allowed to obtain the graduation certificate of the specialty. Otherwise, the invalid course needs to be updated. The specific learning outcome exchange process is shown in Fig. 2.

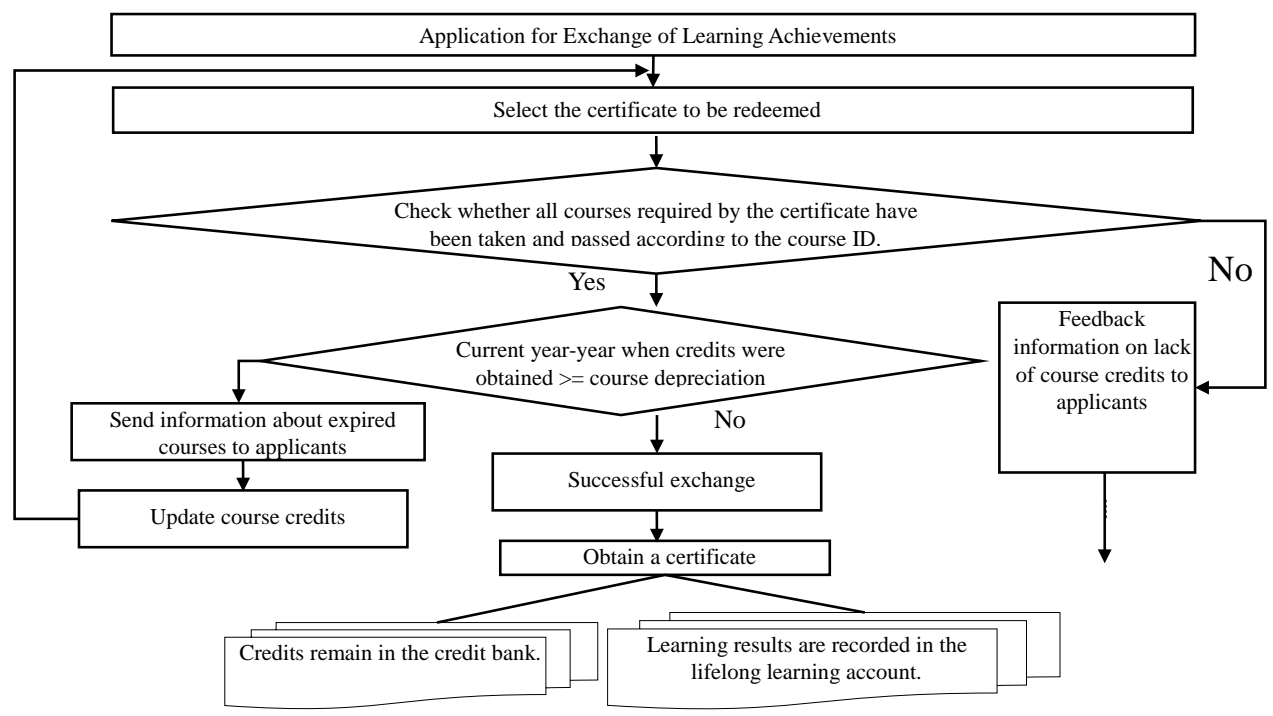

Fig.2. Learning results are recorded in the lifelong learning account 
managing the credit accumulation and learning achievements of the credit bank.

\section{REFERENCES}

[1] Wang Fei and Zhang Liling, "Research Hotspots and Development Trends of CR Credit Bank”. China Adult Education, vol.2019 (7), pp. 66-71. (In Chinese)

[2] Wang Xin, “A Preliminary Study on the Establishment of Rules for Credit Recognition and Conversion under Credit Banking Mode”. Adult Education, vol.2019 (7), pp. 37-42. (In Chinese)

[3] Wang Haidong, "The constituent elements and construction path of the learning outcome certification system”. China Vocational and Technical Education, vol.2018, v.18; pp.12-17. (In Chinese)

[4] Qian Xueping, Chen Puxiang and Huang Kai. "On the Bottleneck of Credit Transfer in Adult Education and Countermeasures Analysis-Taking Shanghai as an Example”. Adult Education, 2018, v.38; No.378(7). pp.11-17. (In Chinese)

The created concept of "course depreciation", and the setting of "course depreciation coefficient bit" in the course code in the credit bank system can solve the contradiction between the prescribed validity period of student status and the lifelong validity of learning achievements, as well as the renewal of subject knowledge and the lifelong validity of course credits, more scientifically and simply exchanging and
[5] Guo Fuqiang, "Construction of the Standard System for Certification China Distance Education, vol.2016 (2), pp.34-42. (In Chinese)

[6] Xie Qingsong. "International Comparison of Qualifications Framework for Vocational Education and Training: Mutual Recognition and Cohesion of Learning Results”. Education and Vocation, vol.2019, 938(10), pp.7-14. (In Chinese) and Transformation of Learning Outcomes under Credit Bank Mode”. 